\title{
INTERACTION OF PROFESSIONAL JARGON AND LINGUISTIC IDENTITY
}

\section{DSc in Linguistics, Professor, Head of Foreign Languages Dpt., Elena Malyuga ${ }^{1}$ DSc in Linguistics, Associate Professor, Dr. Alex Krouglov ${ }^{1}$ Ekaterina Chervontseva ${ }^{1}$}

\author{
${ }^{1}$ Peoples' Friendship University of Russia, Russia
}

\begin{abstract}
The article explores lexical-semantic and functional aspects of intercultural professional communication from the perspective of opposing identities exposed in the context of professional communicative exchange effectuated by people of various national backgrounds.

In an age of multiculturalism, peoples' linguistic identity goes hand in hand with their mentality, which is why the study also considers professional language as a component of both general linguistic system and a type of social dialect. For the purposes of professional communication analysis, the linguistic-semantic approach can be productively applied to investigate terms (codified vocabulary) and professional jargon (uncodified vocabulary) as topical research agendas.

Methodological base of the current research is a complex methodology that combines the following methods of scientific research: linguopragmatic analysis, method of complex analysis of vocabulary units, the method of mass text analysis, the method of componential analysis, and the study material is research and information articles as well as commentaries published in modern specialised magazines, newspapers and their online versions.

This paper aims to review specific codified and uncodified vocabulary featured in dictionary entries and functioning as language units synonymous to the corresponding terms found in social texts. The research material is represented by official printed media materials, as well as transcripts of public speeches and press conference reports delivered by the representatives of the business community. Pursuing the set objective implies addressing the following tasks:

- $\quad$ defining the factors of professional jargon functional diversity;

- $\quad$ identifying the role of linguacultural identity in determining why codified and uncodified vocabulary is being used by English-and Russian-speaking interlocutors in various professional communicative settings.
\end{abstract}

Keywords: intercultural professional communication, codified/uncodified vocabulary, linguistic identity, professional language, linguacultural aspects

\section{INTRODUCTION}

The study of jargon, identification of its primary characteristics, classifications and functions was conducted by many foreign and Russian linguists, such as L.I. Smirnitsky (1956), V.A. Khomyakov (1968), A.D. Schweitzer (1977), E. Partridge (1979), I.V. Arnold (1981), M.M. Makovsky (1982), E.M. Beregovskaya (1996), I.A. Zavgorodny (2002), A.G. Andreeva (2004), M.A. Gracheva (2005), L.Yu. Koroleva 
(2006), I.O. Morozova (2006), E.S. Tarakanova (2006), D.V. Chistyakov (2009), and others.

Professional jargon should not be confused with specialised sublanguages which are distinguished in a precise terminology base in a particular professional sphere [1]. Professional jargons are lexically and stylistically heterogeneous and characterised by their inconsistency and the speed of popular lexis interchangeability.

The lexical-semantic composition of professional language presents one of its key features, along with the level of informational content and the non-codified nature of the lexical and phraseological units used. The language means applied in specific professional spheres can be presented as a system, where all notions are interconnected through logical relations of subordination and coordination. Many linguists $[2,3,4,5]$ view professional language as a terminology system with its core represented by terminology. Such system also incorporates professional jargon, as it denotes notions associated with the rapidly emerging domains of activity and not yet correlated with any officially recognised designations.

Knowing professional jargon and sociocultural factors is instrumental in eliminating typical errors and misunderstandings in communicating with native speakers, which is why researchers have recently been giving careful consideration to uncodified vocabulary. In contemporary linguistics, the term "jargon" refers to words and expressions representative of a specific profession or occupation [6].

Professional communication is commonly described as neutral in terms of the vocabulary used in its production. Business partners are typically expected to avoid emotional vocabulary, metaphors and idiomatic expressions, because business activity inevitably imposes restrictions on people's speech behaviour.

\section{PROFESSIONAL JARGON: GENERAL BACKGROUND}

English professional jargon is a social dialect, which differs from standard English in that it utilises specific lexical and phraseological units and suggests higher level of expressiveness. The representatives of one profession can use professional jargon to name special phenomena that do not have a certain name in general vocabulary. Professionalisms are stylistically substandard synonyms of terms that specify fragments of a particular professional sphere that have not had names earlier, but they do not belong to the specialised terminology. However, they are detailed, nonofficial names of special phenomena and professional notions that have expressive and stylistic connotation, and used in oral speech of people of one profession.

The changes in the language vocabulary are connected with the changes in the society live: scientific and technological progress preconditioned the large scale of processes linked to the 'terminologisation' of the language. There was the rapid growth of the importance of the human focus areas and consequently, it arouses interest to the professional communication. New realias bring their own notions to the professional language, so a lot of specialised words for various scientific notions and objects appear in the language.

Whenever jargon vocabulary units move from one jargon to another, they may undergo changes in terms of both content and form, and act as components of a word combination [7]. When it comes to business communication, professional jargon cannot be neglected, for it accomplishes a specific function, different from that fulfilled by terminology units. 
Some researchers suggest that professional jargons are primarily used in informal settings as part of conversational speech covering professional topics, whereby domain-specific lexical units are used in formal settings in both spoken and written forms [8,9]. Professional jargon can only be used by specialists engaged in the same professional sphere, if the subject of the conversation does not go beyond the specific professional topics.

It was interesting to analyse the implementation of jargon vocabulary in Russian and British advertising texts. The number of such words in advertising sphere has increased considerably. It is related to the fact that advertising is aimed at becoming clearer to any type of audience. The more frequently communicative norms are broken, the more attention is paid to advertising jargon. It is easier to realise expressive and communicative functions by means of jargon.

Professional communication requires codified language system.

One of the bright features of the modern professional discourse is the tendency to use professional jargon. Mixture of conversational, public and professional styles of speech occur nowadays. However, limitation of themes and participants of the professional discourse influence lexical means choice.

Professional themes became the cause of professional jargon use by the businessmen community more often than professional terminology.

In this paper we researched professional jargon which presents dialectical unity of language features, i.e. combination of linguistic and extralinguistic factors.

Professional jargon helps establish very close contact among business partners due to its narrow orientation, expressiveness, laconicism and uncommonness.

Professional jargon is typically highly metaphorical in nature. Bearing manifold functions and meanings, a metaphor implies a wide range of interpretations. Metaphorical transfer may be premised on similarity underlined in the context of various features, such as colour, sound, form, physical action, sensation, size, time, taste, smell, attribute, etc.

Metaphorical transfer is viewed as one of the key means in generating English professional jargon, fulfilling a number of functions in business discourse, designating new specific phenomena with existing nominations, figuratively explaining special terms, making the speech more emotional and expressive. A metaphor does not suggest literal apprehension, which is why it is inseparable from the context.

In "the Economist" one can meet different examples of metaphorical transfers:

- Given France's reputation as the most anti-American country in Europe, it seems odd that McDonald's revival in Europe is being led by a Frenchman, using ideas cooked up in the French market.

- The Company has too many balls in the air.

- Wearing too many hats makes employees less productive.

Professional jargon and terminology (professional vocabulary) need to be differentiated, as the latter refers to the words and expressions nominating the notions referring to different spheres of people's professional activity, different areas of expertise, and do not present commonly used units, but are rather used by a limited community affiliated through professional background.

\section{PROFESSIONAL JARGON AND LINGUISTIC IDENTITY}


Linguistic studies concerned with identity issues are closely aligned with the investigations on professional communication. This prompts a review of general scientific paradigms presented in the realm of language studies [10,11]. The issue of the linguistic identity is closely related to the issue of research methodology. The underlaying premise in modern studies of linguistic identity is the understanding of this phenomenon as a construction that is formed due to the influence of diverse cognitive mechanisms of self-identification and communicative strategies of self-cognition.

Today the study of the identity is not just a domain of philosophy, sociology, psychology and cultural studies; it is also rather topical issue in contemporary linguistics and connected with the development of modern society and humanitarian knowledge.

Speaking about language identity it is necessary to understand what linguistic means and constructions signal about the topicality of different identity models, in other words, which word or word combination can become a marker of identity.

Language is a tool helping apprehend one's own and alien cultures. Professional communication broadens the cultural horizon and the knowledge of the world. In their attempts to surmount the ethnocentrism (which inevitably occurs whenever cultures are being compared), some linguists use language universals, which can be defined as words used in a professional language $[12,13]$.

The sheer opportunity to use these universals seems perfect. However, whenever actual communication comes into focus, there are commonly two cultures subjected to contrastive analysis: one's own culture and an alien culture. Yet this kind of juxtaposition results in some sort of compromise - intercultural communication, which, in its turn, furthers manifestation of one's own identity.

Language is one of the crucial means helping people get accustomed to their own and alien cultures, and comprehend their personal identities. People speaking several languages are empowered to expand their cultural horizon and tune into multiple cultures, which ultimately contributes to their self-identification [14].

Professional discourse is under the influence of the professional language. So the new words penetrating into the recipient language become clear for the native speakers.

Many transnational companies prefer to use slogans in English. For example:

- "The way ahead" - Panasonic; - «Дорога вперед».

- "Your own way" - Camel; - «Это твой путь».

- "It's a Sony" - Sony; - «Это Sony».

- "Made in Paradise" - Renault; - «Созданный в раю».

- "We make light work" - Erco; - «У нас работа спорится» .

- "You'll be impressed" - General Motors; - «Вы удивитесь».

- "There is no better way to fly" - Lufthansa; - «Нет лучше способа летать».

- "You've got the power" - Prince - «Теперь вы сильные» [15]

A prominent peculiarity of contemporary professional communication is a tendency towards abundant use of professional jargon, whereby conversational, public and business-and-professional registers are being merged into one. Notably, today the boundaries separating different registers are becoming ever more blurred.

Professional jargon makes both spoken and written language more attractive, which mainly has to do with its being expressive, concise and unconventional in nature. Lexical and phraseological units of professional jargon are stylistically reduced 
synonyms of literary terms. Their occurrence in speech serves as a kind of reference point helping estimate professional affiliation. For example:

- $\quad$ Face lifting meaning rebranding;

- $\quad$ Best ager meaning mature consumers with high purchasing power;

- $\quad$ Word of mouse meaning information spread via Internet;

- $\quad$ Dog and pony show meaning a well-prepared advertising campaign.

The global changes in modern society related to the constantly developing opportunities of mass communication, availability of mass media influence not only standards of living, but also the way of thinking and the system of perception of a person and, consequently, the linguistic identity.

The studies show how the language forms the various expressions of identity and how it reflects them, how the language creates and represents the professional groups. The connection between the language and the identity considered in the present research helps people understand how the social and professional world that surrounds us is developed.

\section{CONCLUSION}

Study findings give insight into the interconnection of language and identity, the correlation of personal and socio-cultural identity as exemplified by terms and professional jargon used in professional speech interaction to convey speakers' communicative intentions and establish a specific communicative setting. Extralinguistic and linguistic factors proper facilitate further expansion of the lexicalphraseological composition of professional language.

Metaphor is viewed as one of the key stylistic means contributing to professional jargon expressiveness.

The analysis illustrates that professional jargon, registered in both written and spoken language, bears evidence of the informal nature of communication, whereby literary language is being adapted through the transfer of meaning only apprehensible to the members of a given professional group and bearing figurative, sarcastic, ironic or parodic emotional connotation.

Our research considers the relations between the professional jargon and conditions of its functioning in a particular communicative and pragmatic space (advertising media discourse) in terms of pragmalinguistics. The interaction here is between the speaker/writer and listener/reader.

The pragmatic components encourage the implementation of those linguistic phenomena that adequately express the communicative intentions of a speaker and correspond to a certain communicative environment.

It is worth pointing out that the analysis of means of professional jargon implementation and functioning within the language is of great interest from the prospective of semantics as well as communicative and cognitive pragmatics as professional jargon contains information about the world around us that is to be transmitted during the communicative act and used in humans' cognitive activity.

Thus, it can be stated that from the perspective of the linguistic-pragmatic framework, which deals with the communicative implications governing the operation of codified and uncodified vocabulary, the focus of attention is being shifted towards the relationship between professional jargon and its modus operandi within a specific communicative-pragmatic sphere (professional communication), as well as the peculiarities of speaker/recipient interworking. 
Therefore, professional jargon can be referred to as a set of simplified words denoting notions used by professionals of a specific domain. Therewith, professional jargon can commonly be used to simplify both spoken and written forms of communication. As the study shows, apart from neutral vocabulary, communicating parties may also resort to professional jargon as emotional-evaluative and figurativeexpressive means of expression.

\section{ACKNOWLEDGEMENTS}

The publication was prepared with the support of the "RUDN University Program 5$100 "$

\section{REFERENCES}

[1] Malyuga E., Tomalin B. English Professional Jargon in Economic Discourse // Journal of Language and Literature. - № 5(4). - 2014. - Pp. 172-181;

[2] Knops, A. "A strategic-relational account of language use, discourse, and reason," Critical Discourse Studies, № 12 (1), pp. 1-19, 2015.

[3] Chistyakov, D.V. Jargonisms as a phenomenon of secondary nomination (a case study of modern German language). PhD thesis. Russia, Moscow, 2009.

[4] Malyuga E., Orlova S. Linguistic pragmatics of intercultural professional and business communication, Germany: Springer, 2017.

[5] Crystal D., My priority for the next 50 years: an online cultural dictionary, Training language and culture, vol. 1, issue 1, 2017, pp. 13-27.

[6] Page, S.E. The difference: how the power of diversity creates better groups, firms, schools, and societies. Princeton, 2008.

[7] Matveeva, T.V. Complete dictionary of linguistic terms. Rostov-on-Don: Phoenix Publications, 2010.

[8] Allen K. and Burridge K. Forbidden Words, Cambridge University Press, 2006.

[9] Adorno, Theodor. The Jargon of Authenticity. London: Routledge, 2009.

[10] Finegan, Edward. Language: Its Structure and Use. Boston, MA: Thomson Wadsworth, 2008.

[11] Friedman, Karen. Shut Up and Say Something: Business Communication Strategies to Overcome Challenges and Influence Listeners. Santa Barbara, CA: Praeger, 2010.

[12] Meyerhoff, Miriam. Introducing Sociolinguistics. Oxon: Routledge, 2006.

[13] Pechter, Edward. - In Defence of Jargon: Criticism as a Social Practice.l Textual Practice 5.2 (2008): 171-182. Web. 16 Aug. 2015.

[14] Vetrinskaya V.V., Dmitrenko T. A., Developing students' sociocultural competence in foreign language classes, Training language and culture, vol. 1, issue 2, 2017, pp. 23-41.

[15] www.slogan.de 